\title{
Critical Success Factors for Leading Hotel Brands in Asia: A Case Study of Banyan Tree
}

\author{
Huawen Shen ${ }^{1}$ \\ ${ }^{1}$ School of Hotel and Tourism Management, The Hong Kong Polytechnic University, Hong Kong \\ Correspondence: Huawen Shen, School of Hotel and Tourism Management, The Hong Kong Polytechnic \\ University, Hong Kong. Tel: 852-6574-5282. E-mail:shenhuawen1980@hotmail.com
}

Received: March 22, 2015

Accepted: April 15, 2015 Online Published: May 31, 2015

doi:10.5539/ijms.v7n3p19

URL: http://dx.doi.org/10.5539/ijms.v7n3p19

\begin{abstract}
This study examines the critical success factors for Banyan Tree hotels which is a brand of Asian origin. Strategic choices, quality product, human resource management and Asianess are identified as four critical factors from three data sources-site visits, websites analysis and in-depth interviews. The implications are also provided for the success development of Banyan Tree hotels as well as Asian hospitality industry.
\end{abstract}

Keywords: Asian hotels, Banyan Tree, critical success factors

\section{Introduction}

Asia's hospitality and tourism industry is well known for providing outstanding service (Wan \& Chon, 2010). In recent years, many Asian hotel brands famous for their high-end service are expanding their network and penetrating markets outside their Asian roots by establishing themselves in Europe and beyond (Kolesnikov-Jessop, 2010).

A number of Asian hotel brands have become global benchmarks in their own right. The 2012 Forbes 5-star list (Forbes Travel Guide 2012 Star Award Winners, 2012) shows that 13 out of 59 5-star hotels and 13 out of 31 5-star spas are Asian brands.

As a brand of Asian origin, Banyan tree has also achieved global recognition. By end of 2008, Banyan Tree managed and/or had ownership interests in 25 resorts and hotels, 68 spas, 65 retail galleries, and two golf courses in 55 locations in 23 countries. Since its establishment in 1994, the company's flagship brand, Banyan Tree, had won some 400 international tourism, hospitality, design, and marketing awards, some of which included the "Best Resort Hotel in Asia-Pacific" (Phuket) for four consecutive years from Business Traveler Awards since 2002, "Seychelles' Best Resort" and "Seychelles' Best Spa" from World Travel Awards (2003), "Best Hotels for Rooms" (Bangkok) from UK Conde Nast Traveler (2006), "Best Hotel (Luxury)" (Lijiang) from Hospitality Design Awards (2007), and"PATA Gold Award - Ecotourism Project Category" (Bintan) from Pacific Asia Travel Association Gold Awards (2008). Banyan Tree had become a leading player in the luxury resort and spa market in Asia. As part of its growth strategy, Banyan Tree had launched new brands and brand extensions that included resorts, spas, residences, destination club memberships, retail outlets, and even museum shops. Now, the company was preparing to aggressively grow its global footprint in the Americas, Caribbean, Europe, and the Middle East while preserving its distinctive Asian identity and strong brand image of Banyan Tree (Wirtz, 2011).

Banyan Tree's success has caused industry experts to examine its quick development as well as analyze the factors contributing to its success among competitors. People continue to question how Banyan tree was able to achieve such success as a representative of Asian hotel brands, ask what contributes to its success and discuss the critical success factors contributing to its position as an Asian leading hotel brand. With all these issues in mind, the current study intends to address the following questions:

1) What factors have contributed to the success of Banyan Tree in Asia?

2) What are the Critical Success Factors (CSFs) of Banyan Tree according to both the guests and corporate executives? 
An examination of the success factors of a leading Asian hotel brand provides further insight into the development of hospitality industry in Asian, and contributes to the existing literature of CSFs in the hospitality industry in general.

\section{Literature Review}

Definitions for CSFs include "the limited number of areas in which satisfactory results will ensure successful competitive performance for the individual, department or organization.”(Bullen \& Rockart, 1981, p. 7); “the areas in which good performance is necessary to ensure attainment of the goals; the few key areas where things must go right for success..." (Geller, 1985, p. 77). Using a CSF approach can illuminate the success of hotels and thus is one method for filling the above mentioned gap. Critical Success Factors are activities required for ensuring the success of a company or organization. CSFs are the factors that must be satisfied to guarantee a company's overall goal attainment (Brotherton, 2004). CSFs can be either internal or external. Internal CSFs reflect a company's core capabilities for its survival in the market such as people, products, process etc. (Berry, Seiders, \& Greshan, 1997; Duchessi, Schaninger, \& Hobbs, 1989). External dimensions, such as competition and market condition, are less manageable (Brotherton \& Shaw, 1996). Nevertheless, external conditions are equally important. At a practical level, CSFs may help researchers and practitioners distinguish necessary elements critical for organizational success from the complex, multi-dimensional reality of business activities (Butler \& Fitzgerald, 1999). Additionally, companies identifying CSFs and implementing their usage, through proper measurement, feedback, and management, received a higher return on equity when compared with companies that did not employ CSFs (Jenster, 1987). While there has been much research concerning CSFs for small businesses in other industries (Haktanir \& Harris, 2005; Venter \& Maas, 2005), relatively little is known about the hotel industry (Geller, 1984; Brotherton \& Shaw, 1996; Brotherton et al., 2003; Brotherton, 2004a, 2004b). Hospitality-related CSF studies reveal the importance of CSFs for the hotel industry. Notable among those studies are Geller's (1985) on the U.S. hotel industry, which focused on the application of the CSF approach to hotel information systems design; and Brotherton and Shaw's (1996), which constituted the starting point in relation to CSFs in "UK Hotels Plc." Brotherton et al. (2003) undertook a study to identify the CSFs in U.K. and Dutch hotels. This was followed by Brotherton's (2004a, 2004b) work to identify CSFs in U.K. budget and corporate hotel operations, respectively. These studies reveal that if firms are to respond to changing competitive business conditions, they must change their ways of thinking about organizations and their structures. Communication, coordination, the internet, and alignment have become critical components of the contemporary way of thinking. One category of CSF literature follows the approach of "goals-CSFS-measures" (Bullen \& Rockart, 1981; Jones, 1995; Geller, 1985). The theory is to indentify information needs through eliciting and identifying: goals, the success factors critical for achieving these goals, and measurement criteria from the relevant individuals in a business or association. Geller's study, for example, applied the CSF approach to the design of hotel information systems. He began by exploring the generic CSFs common to most hotels. In his research, he interviewed 74 executives of all kinds of hotels-large and small, old and new, private and public. They explained their hotel goals and the CSFs they utilized to achieve their goals. The top 9 CSFs identified were: employee attitude, guest satisfaction, superior product and location, maximizing revenue, cost control, increasing market share, increasing customer price-value perception, and achieving market segment. Geller's study focused on top executives. Jones (1995) applied the CS t F approach to identify information needs in UK hotel companies, but used employees in different managerial positions. He was able to generate insightful knowledge on CSFs in the hotel industry. According o Jones' findings, human resource related factors - having the right staff, a good management team, and staff motivation - were of the utmost importance from the general managers' point of view, along with product quality. For department managers or heads, different CSFs were identified depending on the different managerial positions. Having the right kind of staff and staff development were still of critical importance for most of them, though. Another seminal work, which employed a similar application of the CSF approach, by Brotherton and Shaw (1996) tried to identify CSFs among department/Functional levels of hotel operations and creatively made use of a three dimensional model based on the elements of objectives, CSFs, and Critical Performance Indicators (CPIs). They explored CSFs and CPIs within the front office, F \& B, conference and banquet, leisure operations, back of the house, marketing and sales, human resource, accounting and control, and guest accommodations. They concluded that the following factors were most crucial for successful hotel operations: service and customer care, quality of staff including their attitude, skill and appearance, quality of the hotel product, revenue and profit, safety and hygiene, and cost efficiency. CSFs were found to vary from department to department. Other important elements included price and the maintenance of the facility. 
Apart from this group of CSFs, other studies have been done on the success of the hospitality industry that explore generic key factors, strategic choices, external environment, and the organizational resources and competence that lead to success. It has been noted that when people place the hotel industry in a broader context, the factors contributing to hotel success are more complex and multidimensional, and hence less easy to identify. Jogaratnam and Tse (2004, p. 250) emphasized that "hotels with an entrepreneurial stance far perform better than those that stick to the tried and true." After they conducted a survey of 164 hotels in mainland China, Hong Kong, Malaysia and Singapore, they found that entrepreneurial hotels perform better than more conservative ones. This held true even when the hotels needed to address their long term objectives instead of short term ones. The success of Microtel in the US has also been attributed, to a great extent, to the entrepreneurship of its management (Justus, 1991). Graf (2008) discussed two types of CSFs in the context of strategic managementadministrative CSFs and operational CSFs, which addressed the resources and competencies of the organization. Camillo et al.'s (2008) work tackled critical success factors for independent restaurants in Northern California through a more inclusive approach. The five constructs utilized for analysis of the characteristics or factors that lead to the success or failure of a restaurant included: strategic choices, competitive factors, marketing, resources and capabilities, and owner-manager traits.

From the above studies, it can be found out that CSFs vary from organization to organization, and even among the managers within the same organization (Geller, 1985). Different organizations have different priorities in terms of strategies and different perceived critical success factors. However, the critical areas are unique to individual companies-reflecting industry position, age, competitive strategy, environmental factors, management style, financial strength, and so on (Geller, 1985).

Based on the literature, different studies classified success factors for hospitality firms into different categories, but these factors can be generalized into the following aspects: human resource related factors, guest satisfaction, product quality, strategic choices, Managerial Competencies and resources (shown in Figure 1)

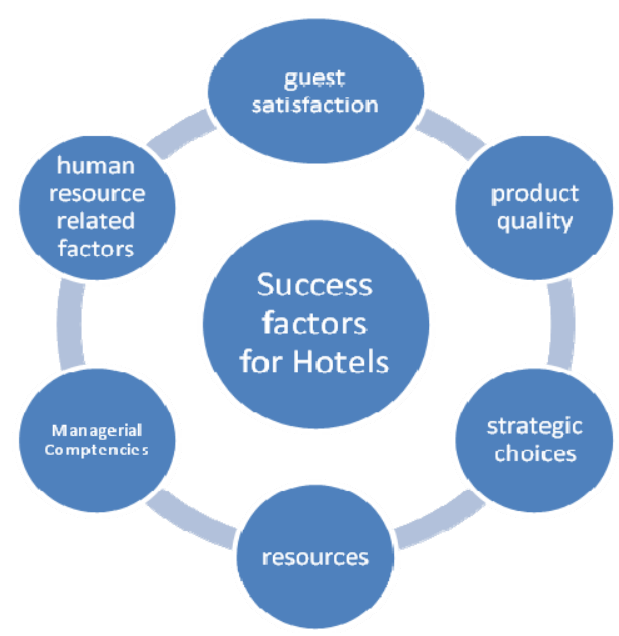

Figure 1. Critical success factors for hotels

\section{Research Methods}

A quality study was used in this study. Qualitative research can probe deeply, uncovering subtle and complex issues using small sample sizes (Jones \& Lee-Ross, 1998). Yin (2003) defines case study as an empirical study that investigates a contemporary phenomenon within its real-life context when the boundaries between phenomenon and context are not clearly evident, and in which multiple sources of evidence are used. It involves in-depth, contextual analysis of matters relating to similar situations. In this study, case study is the primary research technique used for collecting the data, which are from three sources: site visit, hotel's website, interviews with the managers and the guests. The secondary data which focused on literature review was also used in this study.

Firstly, Site visits were conducted. The author visited and stayed overnight in two Banyan tree hotels, one is in Bangkok Thailand; the other is in Hangzhou, China. On-site observation enables the author to experience the products and services of Banyan tree, which enhance the understanding of this hotel. In the meanwhile, through 
observation, customer satisfaction was observed and organizational documents such as human resources policies, strategies, expansion planning are collected. Furthermore, prior to interview, indicators for the success of banyan tree were drawn from hotel booking website-bookings.com. Both positive and negative comments in the past five years (2010-2014) from guests are examined. These indicators or comments were used as probing prompts for further insights during the interview. Apart from these, in-depth interviews were also conducted to explore Banyan tree's CSFs from the perspective of managers, staff and customers respectively. Nine interviewees were invited for this study which includes three management staff, two front-line staff and four customers (shown in Table 1). All the interview questions were developed based on the factors which have been summarized (shown in figure 1). The interview questions can be seen in Table 2 .

Table 1. Profile of the interviewees

\begin{tabular}{lll}
\hline Interviewee & & Background for \\
\hline 1 & Human Resource Manager & 8 years' experiences in the industry \\
2 & Department Manager(Bangkok) & 6 years' experiences \\
3 & Department Manager (Hang Zhou) & 8 years' experiences \\
4 & Front Desk staff (Bangkok) & 2 years' experiences \\
5 & House Keeping staff (Hang Zhou) & 1 year experiences \\
6 & Customer 1 & Germany \\
7 & Customer 2 & French \\
8 & Customer 3 & British \\
9 & Customer 4 & American \\
\hline
\end{tabular}

Table 2. Interview questions

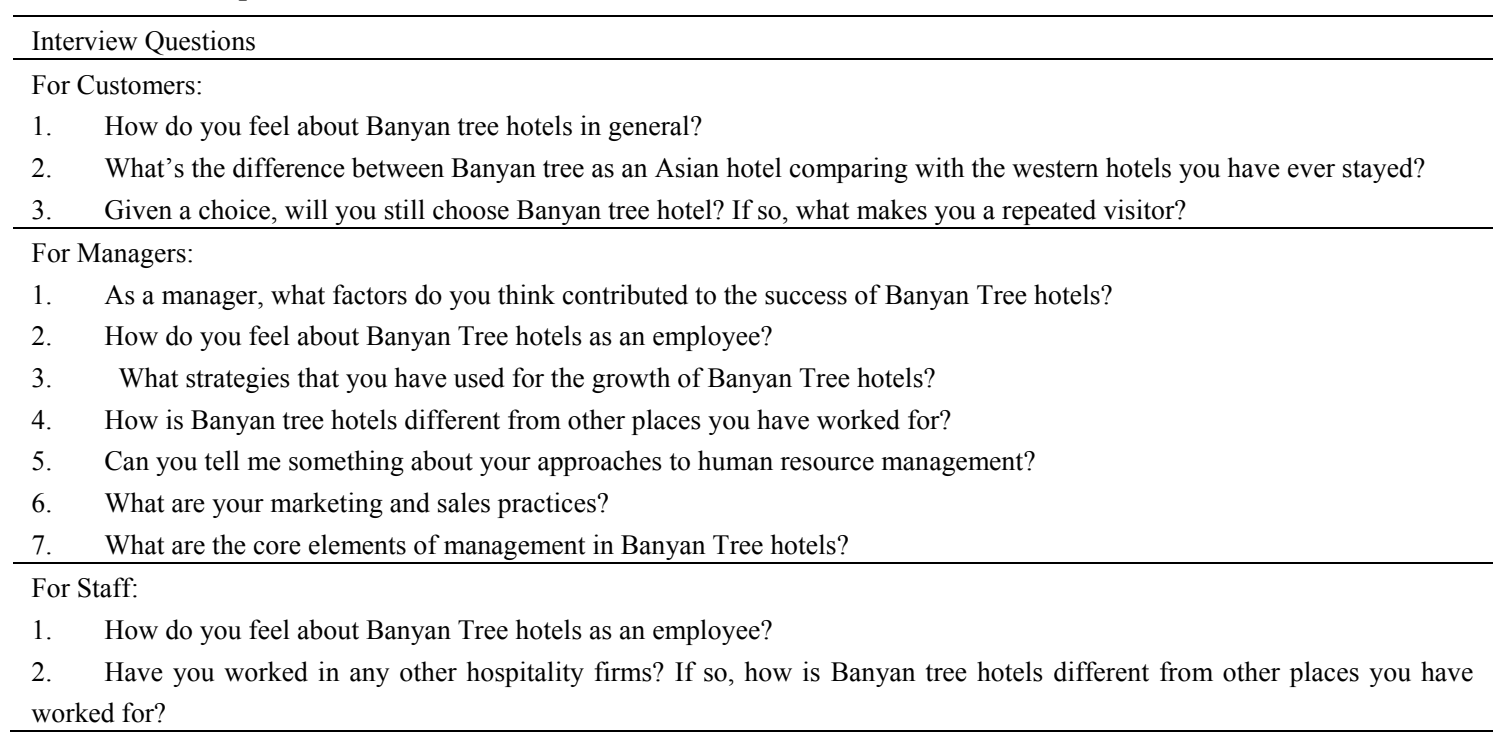

\section{Findings and Discussions}

Based on the study, certain aspects have been identified as the success factors for Banyan tree hotels through interviews, on-site observation and website examination as well as literature review.

\subsection{Strategic Choices}

\subsubsection{Brand Positioning}

Market positioning is ranked number one on the list of Banyan tree's strategies which lead to the success of this hotel chain. The idea of entering the luxury resorts market for Banyan Tree was inspired by the sharp price gap between the luxurious resort hotels such as Aman and other resorts such as shangari-la, the founder of Banyan tree saw potential for offering an innovative niche product that could bridge the price gap in this market (Wirtz $\&$ Koh, 2005). This is also verified from the interviews with management staff when asking them about their target markets comparing with other competitors. Furthermore, all Banyan tree resorts and villas were designed around the concept of providing "a sense of place" to reflect and enhance the culture and heritage of the 
destination. In the meanwhile, the resorts were designed to blend into the natural landscape of the surrounding environment and use the natural foliage and boulders as a privacy screen for creating a sense of exotic sensuality and ensure the privacy of its guests (Wirtz \& Koh, 2005).

\subsubsection{Unique brand marketing strategy}

When Banyan tree was first launched, extensive advertising was carried out for a short period of time to gain recognition in the industry. But soon later, the company scaled down on the advertising. From that time, the entire brand marketing has been based on public relations and global marketing programs, for example, relationships with travel editors and the resorts. This helped increase editorial coverage on Banyan tree, which management felt was more effective in conveying the "Banyan Tree Experience" from an impartial third-party perspective (Wirtz 2011). Furthermore, word-of-mouth recommendation is also another channel for brand marking. As one of the customers mentioned:

I get to know this hotel brand from my girlfriend. She strongly recommends me to stay here.

\subsubsection{Expansion Strategy}

Considering the need of the market on its spa and other products, Banyan tree expanded its network of spas and retail outlet. Nowadays, the Banyan Tree Spas and Banyan Tree Galleries were set up as separate ventures in Singapore, Shanghai, Sydney, India, and Dubai, operating either in other hotels or as stand-alone outlets. In the meanwhile, Banyan tree introduces the Angsana brand in response to demand from hotel operations in Asian that were keen to introduce spas services in their hotels.

As the positioning of these hotels did not fit that of Banyan Tree, the company decided to launch a new brand, Angsana, a more contemporary and affordable brand than Banyan Tree, to run as stand-alone spa businesses in other hotels.

\subsection{Quality Products}

Products consistency and uniqueness are another two characteristics of Banyan Tree hotels. These were noticed during the site visits and interviews.

Guest room facilities, bedding and even the aroma are quite similar in all the Banyan tree hotels. As Guest A stated that:

No matter which city I am in, I prefer to stay in Banyan tree as I can find the familiar aroma and same bedding which make me feel at home.

Management staff B also disclosed:

We maintain consistency in our hotel chains. Management work is done by the people who is sent from our headquarter for those franchised hotels.

Unique products also make Banyan tree hotels different with others and customer satisfaction is their service standard. For instance, in Phuket, a couple could enjoy dinner on a traditional Thai long tail boat accompanied by private Thai musicians while cruising instead of dinning in a restaurant. Banyan Tree Phuket also offered wedding packages in which couples were blessed by Buddhist monks. In Banyan tree Maldives, wedding packages included in an underwater marriage ceremony among the corals. According to Management Staff B,

Our products standard was determined in terms of customer satisfaction rather than typical service standards in the industry.

Similarly, Management staff $\mathrm{C}$ explained:

High empowerment has been given to the staff for providing customers personalized service.

\subsection{Human Resource Management}

Banyan tree hotels have very special philosophy on providing the staff excellent welfare. Employees were taken to and from work in air-conditioned buses, and had access to various amenities, including good-quality canteens, and medical and child care facilities. Staff dormitories had televisions, telephones, refrigerators, and attached bathrooms. One of the management staff mentioned explained:

The generous welfare we provided to the staff is for enhancing their sense of ownership and creating a sense of hospitality, so they can treat customers in the same way.

Apart from this, all employees were trained to greet guests, remember their first names, and anticipate their needs in the basic elements of five-star service establishments. In addition, some employees were required to 
"experience Banyan tree hotels". Management believed that the stay would help employees understand better what guests will experience and in turn, enhance their delivery of special experiences for the guests.

Furthermore, banyan tree also attaché a lot of importance to the creativity and sensitivity of a staff. For example, the housekeeping teams were not restricted by a standard bed decoration. Rather, they were given room for creativity.

\subsection{Asianess}

Asianess is one of the most important factors contributing to the success of Banyan tree hotels. So what is Asianess? According to Chon (2012), Asianess can be explained by unique, distinctive or specific characteristics peculiar to "Asia" and "Asian" people and society. Banyan tree hotels, as an Asia based hotel chains, integrated Asian culture into every aspects of hotels, which includes an exposure of traditions, customs, religion, superstition ceremonies, rituals, the arts, crafts, language, dress, food, architecture, and landscaping etc. In Banyan tree, local or Asia-sensed products are sold in galleries and gift shops, in Thailand hotels, hotel staff will greet guests with the Thai Wai. Asianess can be experienced anywhere in Banyan tree hotels.

Why I choose to stay in Banyan tree everytime when I come to Thaialnd is because I can experience Asian culture here. (Customer C)

Customer B also mentioned that:

Even I stayed in the Hotel in Hangzhou, I can feel and smell this city and this land through the hotel surroundings.

Furthermore, Asian culture has been strongly influence by the Buddhist and Hindu relgions, which share similar roots. The influence of these religions can be seen in many Asian staff demonstrating a natural desire to please and to deliver service from the heart (Wan \& Chon, 2010). All the overseas customers noted:

The service here is very different from European countries. The staff here is more courteous, helpful and caring.

\section{Conclusions and Implications}

This study is qualitative in nature and is case specific. The study examined the CSFs for Banyan tree hotels in Asia from different the perspectives of customers, frontline staff as well as managers and revealed that the most important CSFs are corporate strategies, human resource management, quality product as well as Asianess

Among corporate strategies, brand positioning is taken as the key strategy which leads to the success of banyan tree hotel chains. It is found in the study that proper brand positioning makes the hotel acquire the niche market. More importantly, among all the success factors, human resource management, in another word, people is said to be the most important factors for Banyan tree's success from both corporate executives' and unit managers' points of view. This is in line with Jones' (1995) research findings that having the right kind of staff and management team is the most important factor for success in the service industry. Apart from these, unique product or quality product, which also contributes to the success of banyan tree hotel chains, can't be neglected as well.

One of the most important contributions of this study is that Asianess is identified as a significant success factor for Banyan tree hotels. The results of the study revealed that Asian culture has been integrated into every aspects of the hotel from architecture to the service. This factor has not been mentioned in previous studies. Banyan tree hotels attract a lot of novelty seekers due to its typical Asian characteristics.

Currently, Banyan Tree hotels are planning to expand to Europe and North America. As an Asian based hotel chains with very distinctive Asian characteristics, transferring its success to other parts of the world will face a lot of challenges such as brand dilution under different culture, language barrier and culture barrier when implementing Banyan Tree's special training etc. However, as an Asian hotel company, Banyan Tree hotels' success factors might be very helpful for the development of Asian hospitality industry.

\section{Limitation}

The study has some limitation which should be considered in the interpretation of its findings. Only two study sites were involved in this study and generalizability may be one of the concern. Furthermore, these two hotels are all in Asia. Banyan tree hotel in other parts of the world will probably have different CFs. Moreover, this study interviewed very limited number of guests and frontline management, the involvement of managers from various position and a broader number of guests would be useful for future research. 


\section{References}

Berry, L. L., Seiders, K., \& Greshan, L. G. (1997). For love and money: The common traits of successful retailers. Managing Service Quality, 26(2), 7-23. http://dx.doi.org/10.1016/s0090-2616(97)90002-4

Brothern, B., \& Shaw, J. (1996). Towards an identification and classification of Critical Success Factors in UK Hotels Plc. International Journal of Hospitality Management, 15(2), 113-135. Elesvier. UK. http://dx.doi.org/10.1016/0278-4319(96)00014-X

Brotherton, B. (2004a). Critical success factors in UK budget hotel operations. International Journal of Operation and Production Management, 24(9), 944-969. http://dx.doi.org/10.1108/01443570410552135

Brotherton, B. (2004b). Critical success factors in UK corporate hotels. Service Industries Journal, 24(3), 19-42. http://dx.doi.org/10.1080/0264206042000247740

Brotherton, B., Heinhuis, E., Miller, K., \& Medema, M. (2003). Critical success factors in UK and Dutch hotels. Journal of Services Research, 2(2), 47-78.

Bullen, C. V., \& Rockhart, J. F. (1981). A Primer on Critical Success Factors. Working paper No. 69. Boston, MA. Center for information Systems, Sloan School of Management, MIT.

Burgess, C., Hampton, A., Price, L., \& Roper, A. (1995). International hotel groups: what makes them successful? International Journal of Contemporary Management, 7(2/3), 75-80. MCB University Press. http://dx.doi.org/10.1108/09596119510080664

Butler, T., \& Fitzgerald, B. (1999). Unpacking the systems development process: An empirical application of the CSF concept in a research context. Journal of Strategic Information Systems, 8(4), 351-371. http://dx.doi.org/10.1016/S0963-8687(00)00027-5

Camillo, A. A., Connoly, D. J., \& Kim, W. G. (2008). Success and Failure in Northern California: Critical Success Factors for Independent Restaurant. Cornell Hospitality Quartely, 48, 364-380. http://dx.doi.org/10.1177/1938965508317712

Chon, K. (2012). Notes for Asian Paradigm in hospitality management. Hong Kong Polytechnic University, DHTM Programme.

Duchessi, P., Schaninger, C. M., \& Hobbs, D. R. (1989). Implementing a manufacturing planning and control systems. California Management Review, 31(3), 75-90.

Forbes Travel Guide 2012 Star Award Winners. (2012). Retrieved September 2, 2012, from Startle: http://www.startle.com/about/awardwinners

Geller, A. N. (1984). Executive information needs in hotel companies. Houston, TX: Peat Marwick, Mitchell and Co.

Geller, N. (1985). Tracking the Critical Success Factors for Hotel Companies. Cornell Hotel and Restaurant Administration Quarterly, 25(4), 76-81. http://dx.doi.org/10.1177/001088048502500414

Graf, N. S. (2008). Industry critical success factors and their importance in strategy. In Olsen \& Zhao (Eds.), Handbook of Hospitality Strategic Management. Elsevier. http://dx.doi.org/10.1016/b978-0-08-045079-7.00004-1

Haktanir, M., \& Harris, P. (2005). Performance measurement practicein an independent hotel context-A case study approach. InternationalJournal of Contemporary Hospitality Management, 17(1), 39-50. http://dx.doi.org/10.1108/09596110510577662

Jenster, P. V. (1987). Using critical success factors in planning. Long Range Planning, 20, 102-109. http://dx.doi.org/10.1016/0024-6301(87)90160-9

Jones, T. A. (1995). Identifying managers' information needs in hotel companies. In Harris, P. (Ed.), Accounting and Finance for the International Hospitality Industry. Oxford: Butterworht-Heniemann.

Jongaratnam, G., \& Tse, E. (2004). The Entrepreneurial Approach to Hotel Operations: Evidence from the Asia-Pacific Hotel Industry. Cornell Hotel and Restaurant Administration Quarterly, 45(3), 248. http://dx.doi.org/10.1177/0010880404266192

Kolesenikov-Jessop, S. (2010). Asian Hotel Brands Make the Journey to Europe. The New York Times. Singapore. 
Venter, E. C., \& Maas, B. G. (2005). The influence of successor related factors on the succession process in small and medium sized family businesses. Family Business Review, 18(4), 283-303. http://dx.doi.org/10.1111/j.1741-6248.2005.00049.x

Wan, S., \& Chon, K. (2010). Asianess-An Emerging Concept in Hospitality Management. Asia-Pacific CHRIE (pp. 175-186). Phuket: The $8^{\text {th }}$ APacCHRIE Conference 2010.

Wirtz \& Koh. (2005). Banyan Tree-Developing a Powerful Service Brand. Service Marketing in Asia-A Case Book.

Wirtz, J. (2011). The Banyan Tree: branding the intangible. Eerald Emerging Markets Case Studies. http://dx.doi.org/10.1108/20450621111110474

Yin, R. (2003). Case Study Research, design and methods (3rd ed.). London: Sage Publications.

\section{Copyrights}

Copyright for this article is retained by the author(s), with first publication rights granted to the journal.

This is an open-access article distributed under the terms and conditions of the Creative Commons Attribution license (http://creativecommons.org/licenses/by/3.0/). 